\title{
Study on Hybrid Filtering Solution for Marine Electric Network
}

\author{
Xiao-Yan Xu, Prof. \\ Shanghai Maritime University, Shanghai 200135, China \\ Janusz Mindykowski, Prof. \\ Gdynia Maritime University \\ C. L. Philip Chen, Prof. \\ University of Macau, Macau, China
}

\begin{abstract}
This paper presents a Hybrid APF/PFC/PPF Circuit (active power filtering and power factor correction circuit aided by shunt passive filter) for harmonic suppression and power factor correction in a marine electric network. By employing the proposed hybrid circuit, marine electric power network voltage and current can be maintained as being sinusoidal, and the power factor is close to 1. The effectiveness of the proposed method that is applied to a marine electric network is demonstrated through a simulation experiment. The results show that the expected performances are achieved.
\end{abstract}

Keywords: Electrical engineering, marine vehicle power systems, power system harmonics, power system measurements, quality control

\section{INTRODUCTION}

Recently, application of power electronic devices to marine systems has been wider and wider, which can be seen from the fact that the number of power electronic devices equipped in ships is increasing very quickly and the capacity of these devices in ships is becoming larger and larger. As a result, in a ship, electrical power energy consumed by power electronic devices occupies a continuously increasing proportion of the gross electrical energy produced by the ship. But harmonics produced by power electronic devices such as frequency converters or soft starters cause distortion of the current waveform and voltage waveform of the electric network, as well as having a remarkable influence on safety and capacity in the choice of electric network, which makes harmonic pollution in a marine electric network more and more serious and difficult to estimate $[11,16]$. Furthermore, impedances of generators designed for ships are relatively higher than those of overland power sources, which worsens current distortion in marine electric networks. Another problem of marine electrical power quality is a low power factor. The selected capacity of ship equipment is usually very conservative and its power factor during routine operation is correspondingly lower since a marine electric network is a kind of low capacity isolated network when compared with an electric network that operates on shore. But the reliability of ship operation plays a vital role in safety of navigation, which leads to a substantial safety consideration in the design of a marine electric network. This is evident in the rules of marine electric network power quality issued by the majority of shipping classifications in the world, which are not less strict, or are even stricter, than the rules of public electric network power quality issued in international standards $[4,13,14,17]$. For example, the limit of stable voltage adjusting rate is between $+2.5 \%$ and $-2.5 \%$ as ruled by the China Classification Society, and the limit of stable voltage fluctuation is $3.3 \%$ in IEC EMC 61000-3-11 $[4,5]$. As another example, the limit of total voltage harmonic distortion $\left(\mathrm{THD}_{\mathrm{V}}\right)$ is $5 \%$ as shown in the national standards of low voltage $(0.38 \mathrm{kV})$ public electric network of China, while comparatively, the mentioned parameter ruled by DNV (Det Norske Veritas - Norwegian classification society) and ABS (the American Bureau of Shipping) is 5\% too. But the fact is, it is more difficult to obtain an improvement of the power quality of a marine electric network than that of an overland electric network due to the characteristics of marine electric networks [10].

Hitherto, the majority of achievements in the field of product design for power quality improvement have been restricted to overland electric networks. There is still a lack of reports showing significant progress of power quality improvement technology applied to ship electric networks. Nevertheless, even considering the practical products which have been applied to overland electric networks, their applied effect has not been satisfactory due to the limitation of control effect and the accuracy of measurement of the electric network in the aspects of active power, reactive power, power factor and high order harmonics. That is, it is reasonable to design a new circuit for a marine electric network to depress harmonics and correct the power factor under the consideration of characteristics of a marine electric network 


\section{HYBRID APF/PFC/PPF CIRCUIT}

\section{Definitions of harmonic distortion and power factor}

Normally, distorted power, based on Budeanu's concept, is defined as [18]:

$$
\mathrm{D}=\sqrt{\mathrm{S}^{2}-\mathrm{P}^{2}-\mathrm{Q}^{2}}
$$

The most popular parameters describing the abovementioned distortions are the total harmonic distortion coefficients $\mathrm{THD}_{\mathrm{V}}$ and $\mathrm{THD}_{\mathrm{I}}$, voltage and current respectively, as shown in formulas (2) and (3).

$$
\begin{aligned}
& \mathrm{THD}_{\mathrm{V}}=\frac{\sqrt{\sum_{\mathrm{n}=2}^{\mathrm{n}_{\max }} \mathrm{V}_{\mathrm{n}}^{2}}}{\mathrm{~V}_{1}} \\
& \mathrm{THD}_{\mathrm{I}}=\frac{\sqrt{\sum_{\mathrm{n}=2}^{\mathrm{n}_{\max }} \mathrm{I}_{\mathrm{n}}^{2}}}{\mathrm{I}_{1}}
\end{aligned}
$$

where $\mathrm{V}_{1}$ is root mean square value of the fundamental harmonic, $\mathrm{n}$ is order of harmonics, and $\mathrm{V}_{\mathrm{n}}$ is harmonic voltage when the order is n. Normally, THD $\mathrm{V}_{\mathrm{V}}$ and THD are obtained when $n_{\max }$ is 40 or 50 , where $n_{\max }$ is the highest harmonic order in the process of defining THD $_{\mathrm{V}}$ or $\mathrm{THD}_{\mathrm{r}}$.

The definition of power factor is shown in formula (4), where total power factor $\lambda$ is the arithmetic product of displacement power factor $\lambda_{\varphi}$ and the distortion power factor $\lambda_{D}$. Formulas (5) and (6) show the definitions of $\lambda$ and $\lambda_{\mathrm{D}}$ respectively. The total power factor $\lambda$ can be described as formula (7), where $\mathrm{S}_{1}$ is the apparent power under fundamental frequency, $\mathrm{P}$ is active power, $\mathrm{Q}$ is reactive power, D is distorted power and $\mathrm{S}$ is apparent power.

$$
\begin{gathered}
\lambda=\lambda_{\varphi} \cdot \lambda_{\mathrm{D}} \\
\lambda_{\varphi}=\frac{\mathrm{P}}{\mathrm{S}_{1}} \\
\lambda_{\mathrm{D}}=\frac{\mathrm{S}_{1}}{\mathrm{~S}}=\frac{\mathrm{V}_{1 \mathrm{rms}}}{\mathrm{V}_{\mathrm{rms}}} \cdot \frac{\mathrm{I}_{1 \mathrm{rms}}}{\mathrm{I}_{\mathrm{rms}}}=\frac{1}{\sqrt{1+\mathrm{THD}_{\mathrm{V}}^{2}} \sqrt{1+\mathrm{THD}_{\mathrm{I}}^{2}}}
\end{gathered}
$$

$$
\lambda=\frac{\mathrm{P}}{\mathrm{S}}=\frac{\mathrm{P}}{\sqrt{\mathrm{P}^{2}+\mathrm{Q}^{2}+\mathrm{D}^{2}}}
$$

The design of harmonic suppression and power factor correction solutions for ship use aims to minimize the quantities of $\mathrm{Q}$ and $\mathrm{D}$ in equation (7) to improve the total power factor $\lambda$ in the marine electric network environment [9].

\section{Design of Hybrid APF/PFC/PPF Circuit}

In this paper, the designed Hybrid APF/PFC/PPF Circuit is a combination of SAPF (series active power filter) and active PFC (power factor correction circuit) aided by a shunt passive filter, which is shown in Fig. 1.

Application of this design takes into consideration that a marine electrical power system is very different from a land power system, because of its character, i.e. an isolated power system, where the capacity of a heavy load in a ship is comparable to that of a ship electrical power station. Moreover, the impedance of generators designed for ships is higher than that of a land power source, which worsens voltage deviations in marine electric networks. Also a heavy load gives an electric network a great impact and causes a considerable voltage drop and frequency oscillations of the electric network at the moment it is switched on. At the same time, power electronic devices generally are used in ship systems and cause distortion of current, and in consequence, voltage waveforms. Taking into account the complexity of the considered matter, it means that the load variation range and variation frequentness, and many kinds of disturbances covering the current as well as the voltage character (including their harmonics) must be considered. At the moment to mitigate harmonics, mainly passive power filters (PPF), and rarely parallel active power filters (APF) in marine technology are used. To improve the dynamic properties of a marine electrical power station and to reduce the power of filtering circuits, a hybrid filter concept for marine electric networks was investigated.

A new type of hybrid solution for a marine electric network was considered as a study and research for the general case of a marine electric network, including voltage sensitive (in the meaning of voltage quality) loads as well as voltage nonsensitive loads. Both of them may be easily appointed in the marine networks, e.g. all computer-aided control, alarm and monitoring systems are strongly sensitive voltage loads, while in contrast the heaters are voltage non-sensitive loads. On the

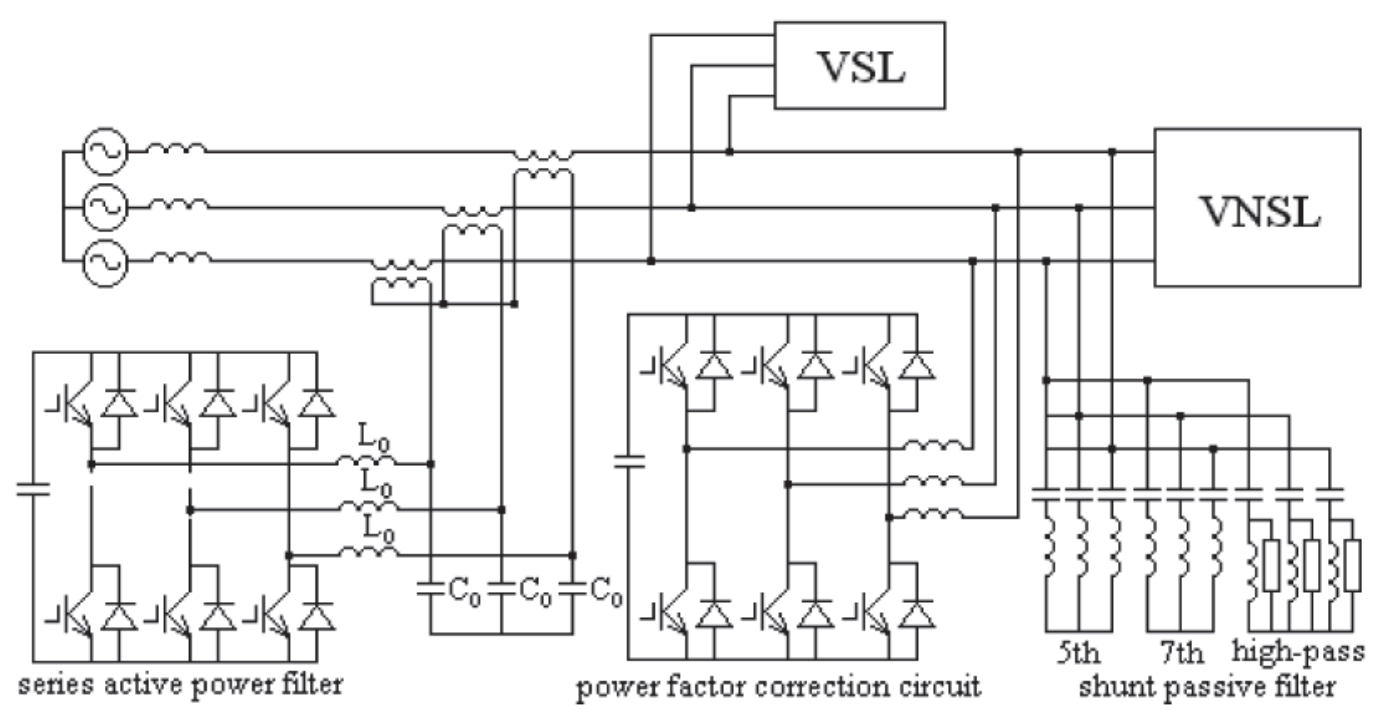

Fig. 1. Configuration of Hybrid APF/PFC/PPF Circuit 
other hand, power converters generate mainly current, but also voltage harmonics, so they generally require a compensation voltage and current harmonics.

In Fig. 1, the SAPF and shunt PF constitute a combined system of series active power filter and shunt passive filter. Based on the following two reasons, the combined series active power filter is designed to be included in the Hybrid APF/PFC/ PPF Circuit. Firstly, the capacity of a marine power station, as well as the capacity of a single generator contained in a power station, becomes higher and higher, but due to the characteristics of a marine generator, source voltage harmonics are rather considerable when compared with those that can be found in an overland network. The SAPF is first of all a controlled voltage source, and it is connected in series between an electrical power supplier and a linear load. The authors have distinguished two kinds of load: one is the voltage sensitive load (VSL) and the second is the voltage non-sensitive load (VNSL). The SAPF can compensate voltage harmonics and improve quality of voltage supplied to the voltage sensitive load (VSL). That is, the SAPF is suitable for harmonic suppression in distorted supply voltages [3]. Secondary, large rated cycloconverters and thyristor converters are more and more frequently applied to marine systems whose capacity occupies an incremental percentage of the total capacity of electrical power. When the combined system of shunt passive and series active power filter is applied, the shunt PF acts as the main bearer to fulfil the task of current filtering, while the series APF does not act rather as a harmonic compensator but mainly as a harmonic isolator. It decreases source harmonics flowing into the shunt $\mathrm{PF}$ and causing resonance. Also the required rating of the series active filter will be reduced to less than $1 \%$, as compared with the rating of a 3-phase 6-pulse thyristor converter or cycloconverter, that is, the required rating of series APF is much smaller than that of a conventional shunt APF [12]. Thereby, application of a combined system of shunt passive and series active power filter results in better filtering characteristics and lower initial and running costs. In the SAPF shown in Fig. 1, $\mathrm{L}_{0}$ and $\mathrm{C}_{0}$ constitute a set of a small capacity filter which is used to suppress high frequency pulsating voltage and current caused by the high frequency switching of the converter.

A combined system of shunt passive and series active power filter is not sufficient for marine electric network application. There are two reasons to develop this filter structure. As mentioned in the first paragraph of this work, the problem of a low power factor may cause a serious problem in ship electric networks and even cause breakdown of an electrical power station during the starting process of bulk load. SAPF is able to improve the operational environment mainly for loads generating voltage harmonics. In contrast, a shunt APF is very effective in depression network current harmonics, usually generated by a non-linear load. Furthermore, the effect of network current harmonic mitigation is not so effective due to the inherent deficiencies of shunt PF, which, undoubtedly, contributes to suppressing the majority of current harmonics. In the authors' opinion a solution is to include an active PFC (power factor correction) circuit in the Hybrid APF/PFC/ PPF Circuit. The active PFC circuit is expected to solve the problem of the low power factor in the electric network, and simultaneously acts as a current harmonic filter to suppress network current harmonics additionally. Taking that into consideration, the active PFC circuit is located between the SAPF and the shunt PF.

While both the combined system of shunt passive, the series active power filter and the active PFC circuit are concerned, each of these works as a supplementary means of the other one, and they work together to suppress harmonics and compensate reactive power at the same time more effectively, assuming that superiorities of different types of compensation devices are mutually complementary. It is also anticipated that, for a marine electric network - an independent small capacity electric network in a complex environment and requiring a quick response to harmonics suppression and reactive power compensation - the proposed solution will meet the demand of a marine electric network for high-speed and accurate measurement and management of harmonics and reactive power. Moreover, taking into consideration the possibility of harmonics suppression and reactive power compensation, the suggested solution will lead to the achievement of significant energy saving.

\section{Control algorithm of Hybrid APF/PFC Circuit}

The key technology to achieve a rapid and accurate effect of electric power quality compensation in ship electric networks, considering the application of the Hybrid APF/PFC Circuit, is the high operational performance of the SAPF and the active PFC circuit in the Hybrid APF/PFC Circuit due to the complicated operational environment of ship loads and high frequency of a wide range of variation of load operating mode.

For an active power filtering or an active power factor correction circuit, the detection circuit of harmonics and reactive current is an important part that determines its compensation characteristics. Generally speaking, in practical application, there are two major types of harmonics and reactive current detection methods. One is based on series expansion of Fourier Transform [2], while the other is based on the theory of Instantaneous Reactive Power of a 3-phase circuit, also called the p-q method [1]. The former method is able to detect a detailed values of harmonics series or the harmonics of a specified frequency band, which qualifies it for fault diagnosis and protection of the electric network, but its real time operational property of current detection is not satisfactory. The latter method has quite good properties in real time detection but is not able to work effectively when the source voltage is distorted [19]. Nevertheless, the theory of Instantaneous Reactive Power of a 3-phase circuit has been the most used until now in the control of active power filters [15]. Of course, there are quite a number of other types of harmonics detection methods, e.g., the adaptive harmonic current detection method [8] and the predictive current detection method [6]. The fact is that all these proposed methods are still in the stage of research and development and lack practicability. A current detection method based on an improvement of the Instantaneous Reactive Power theory of a 3-phase circuit, which is called the $i_{p}-i_{q}$ method, is being developed to effectively detect load current and divide the load current into the fundamental active component, fundamental reactive component and harmonic component with accuracy and real-time property even when the source voltage is distorted or 3-phase unbalanced [19]. Its working principle is expressed concisely in this paper by Fig. 2 .

In Fig. 2, voltage vector $V_{a}$ stands for phase A voltage of power source, with its instantaneous value $v_{a}=V_{m} \sin \omega t$, where, $\mathrm{V}_{\mathrm{m}}$ is amplitude of phase voltage. It provides a PLL (phaselocked loop) circuit with the phase information of sin $\omega t$ and $\cos \omega \mathrm{t}$, with appropriately defined signs. In this detection and control system, three types of coordinates are involved, among which the " 3 -phase coordinate" and " $\alpha \beta$ coordinate" are static coordinates and the "pq coordinate" is a rotary coordinate with its angular velocity $\omega$ - the angular velocity of source voltage. The quantities $i_{a}, i_{b}, i_{c}$ are the detected 3 -phase line currents of the electrical power network respectively. 

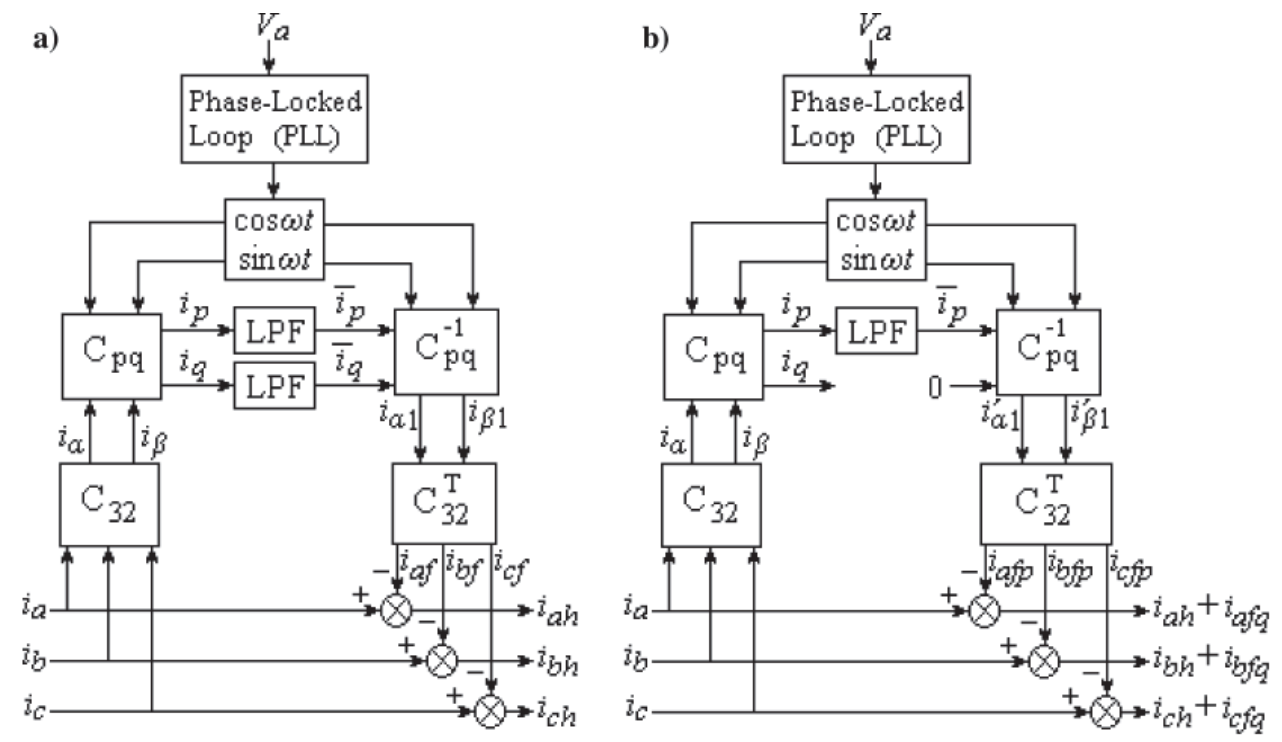

Fig. 2. Fundamental principle of the compensation current determined by $i-i$ method,

a) detection of harmonic current, b) detection of the sum of harmonic current and reactive current

In Fig. 2a, $i_{a}, i_{1 h}, i_{\text {ch }}$ are the 3-phase harmonic currents respectively and $i_{\text {af }}, i_{b f}, i_{\text {cf }}$ are the 3 -phase fundamental currents respectively. In Fig. $2 \mathrm{~b}, \mathrm{i}_{\mathrm{afp}}, \mathrm{i}_{\mathrm{bfp}}, \mathrm{i}_{\mathrm{cfp}}$ are the 3 -phase fundamental active currents respectively, and $i_{\text {afq }}, i_{\text {bfq }}, i_{\text {cfq }}$ are the 3 -phase fundamental reactive currents respectively.

The relationship of the variations in Fig. 2 is:

$$
\left[\begin{array}{l}
\mathrm{i}_{\mathrm{p}} \\
\mathrm{i}_{\mathrm{q}}
\end{array}\right]=\mathrm{C}_{\mathrm{pq}}\left[\begin{array}{l}
\mathrm{i}_{\alpha} \\
\mathrm{i}_{\beta}
\end{array}\right]=\mathrm{C}_{\mathrm{pq}} \mathrm{C}_{32}\left[\begin{array}{l}
\mathrm{i}_{\mathrm{a}} \\
\mathrm{i}_{\mathrm{b}} \\
\mathrm{i}_{\mathrm{c}}
\end{array}\right]
$$

where:

$$
\begin{aligned}
& \mathrm{C}_{32}=\sqrt{\frac{2}{3}}\left[\begin{array}{ccc}
1 & -1 / 2 & -1 / 2 \\
0 & \sqrt{3} / 2 & -\sqrt{3} / 2
\end{array}\right] \\
& \mathrm{C}_{\mathrm{pq}}=\left[\begin{array}{cc}
\cos \omega \mathrm{t} & -\sin \omega \mathrm{t} \\
-\sin \omega \mathrm{t} & -\cos \omega \mathrm{t}
\end{array}\right]
\end{aligned}
$$

So the fundamental current is:

$$
\left[\begin{array}{l}
\mathrm{i}_{\text {af }} \\
\mathrm{i}_{\mathrm{bf}} \\
\mathrm{i}_{\mathrm{cf}}
\end{array}\right]=\mathrm{C}_{32}^{\mathrm{T}} \mathrm{C}_{\mathrm{pq}}^{-1}\left[\begin{array}{l}
\overline{\mathrm{i}}_{\mathrm{p}} \\
\overline{\mathrm{i}}_{\mathrm{q}}
\end{array}\right]
$$

where $\mathrm{C}_{\mathrm{pq}}^{-1}$ is the inverse matrix of $\mathrm{C}_{\mathrm{pq}}$, and $\mathrm{C}_{\mathrm{pq}}^{-1}=\mathrm{C}_{\mathrm{pq}} \cdot \mathrm{C}_{32}^{\mathrm{T}}$ is the transposed matrix of $\mathrm{C}_{32}$. The output of LPF (low pass filter), $\overline{\mathrm{i}}_{\mathrm{p}}$ and $\overline{\mathrm{i}}_{\mathrm{q}}$, are the direct current value of $\mathrm{i}_{\mathrm{p}}$ and $\mathrm{i}_{\mathrm{q}}$ respectively. $\mathrm{I}_{\mathrm{af}}$, $\mathrm{i}_{\mathrm{bf}}, \mathrm{i}_{\mathrm{cf}}$ are 3-phase fundamental currents respectively. Afterwards, the compensation current of harmonic current is:

$$
\left[\begin{array}{l}
\mathrm{i}_{\mathrm{ah}} \\
\mathrm{i}_{\mathrm{bh}} \\
\mathrm{i}_{\mathrm{ch}}
\end{array}\right]=\left[\begin{array}{l}
\mathrm{i}_{\mathrm{a}} \\
\mathrm{i}_{\mathrm{b}} \\
\mathrm{i}_{\mathrm{c}}
\end{array}\right]-\left[\begin{array}{l}
\mathrm{i}_{\mathrm{af}} \\
\mathrm{i}_{\mathrm{bf}} \\
\mathrm{i}_{\mathrm{cf}}
\end{array}\right]
$$

Based on the aforementioned harmonic signals which are obtained according to the $\mathrm{i}_{\mathrm{p}}-\mathrm{i}_{\mathrm{q}}$ method, activity of appropriate filters can be fulfilled.

In the designed SAPF/PFC circuit, considering that the conventional source voltage provided by a ship electrical power station is distorted in evidence and even a little bit 3 -phase unbalanced in a degree, the $i_{-}-i_{\text {method }}$ is applied to determine the compensation current. Furthermore, in Fig. 2b, the channel of current $i_{i}$ is disconnected, then the signal $i_{q}$ that goes through the LPF is 0 , and the equation (8) becomes:

$$
\left[\begin{array}{l}
\mathrm{i}_{\text {afp }} \\
\mathrm{i}_{\text {bfp }} \\
\mathrm{i}_{\text {cfp }}
\end{array}\right]=\mathrm{C}_{32}^{\mathrm{T}} \mathrm{C}_{\mathrm{pq}}^{-1}\left[\begin{array}{c}
\overline{\mathrm{i}}_{\mathrm{p}} \\
0
\end{array}\right]
$$

where only active current can be found in its output of $i_{\alpha 1}^{\prime}$ and $i_{\beta 1}^{\prime}$, that is, the output of transposition of coordinate converter $\left(\mathrm{C}_{32}^{\mathrm{T}}\right)$ leaves fundamental active current only. The difference in value between the detected current $\left(i_{a}, i_{b}, i_{c}\right)$ and the output of $\mathrm{C}_{32}^{\mathrm{T}}$ is the sum of fundamental reactive current $\left(\mathrm{i}_{\text {afq }}, \mathrm{i}_{\mathrm{bfq}}\right.$, $\left.i_{\text {cfg }}\right)$ and harmonic current $\left(i_{a h}, i_{b h}, i_{c h}\right)$. At that time, the final result of current calculation in Fig. $2 b$ expresses the sum of harmonic current and fundamental reactive current. When this result acts as the instruction value of the compensation current, the compensation of fundamental reactive current and the compensation of harmonic current are able to be fulfilled simultaneously. Furthermore, since the method of 3-phase asymmetry control is adopted, the negative sequence current produced by the system itself counteracts the input negative sequence current, so that the simultaneous compensation of negative sequence current is realized [7].

The reactive and harmonic current detection algorithm adopted in the active PFC circuit in the Hybrid APF/PFC Circuit is the $\mathrm{i}_{\mathrm{p}}-\mathrm{i}_{\mathrm{q}}$ method as shown in Fig. 2b, which is under consideration for its function of both power factor correction and harmonic current compensation, and the source voltage is distorted in ship electric networks.

For the SAPF, in order to compensate harmonic voltage accurately and in real time, its harmonic voltage detection algorithm is similar to the harmonic current detection algorithm which is shown in Fig. 2a, where supplied voltage of $v_{a}, v_{b}, v_{c}$ are measured from the output of the power supplier, then $v_{p}$ and $\mathrm{v}_{\mathrm{q}}$ are obtained through matrix transform of $\mathrm{C}_{32}$ and $\mathrm{C}_{\mathrm{pq}}{ }^{\mathrm{p}}$, and after the low pass filter, $\bar{v}_{\mathrm{p}}$ and $\bar{v}_{\mathrm{q}}$, which are DC quantities of $\mathrm{v}_{\mathrm{p}}$ and $\mathrm{v}_{\mathrm{q}}$ corresponding to 3-phase fundamental voltages $\mathrm{V}_{\mathrm{af}}, \mathrm{V}_{\mathrm{bf}}, \mathrm{V}_{\mathrm{cf}}$, are obtained.

After matrix transform of $\mathrm{C}_{\mathrm{pq}}^{-1}$ and $\mathrm{C}_{32}^{\mathrm{T}}, 3$-phase fundamental voltages $\mathrm{v}_{\mathrm{af}}, \mathrm{v}_{\mathrm{bf}}, \mathrm{V}_{\mathrm{cf}}$ are detected. Afterwards, harmonic voltages $\mathrm{V}_{\mathrm{ah}}, \mathrm{V}_{\mathrm{bh}}, \mathrm{V}_{\mathrm{ch}}$ are obtained, according to which the 3-phase instruction voltage of the power electronic converters, corresponding to $-\mathrm{V}_{\mathrm{ah}}$, $-\mathrm{V}_{\mathrm{bh}},-\mathrm{V}_{\mathrm{ch}}$, are ascertained and adopted to control the on-off state of the six switching units in the main circuit.

For the shunt passive filter in the Hybrid APF/PFC/PPF Circuit, its parameters are designed according to the L-C Resonance Principle to suppress the $5^{\text {th }}$ and $7^{\text {th }}$ order current 
harmonics, as well as higher order current harmonics, caused by the nonlinear load while it operates in rated conditions, since the eigenvalue of harmonics caused by the adopted nonlinear load is $5^{\text {th }}$ and $7^{\text {th }}$ order harmonics, $11^{\text {th }}$ and $13^{\text {th }}$ order harmonics, etc. The operational performance is not so satisfactory if the shunt passive filter operates alone, for a shunt passive filter does not employ any control algorithm and its parameters are fixed.

\section{SIMULATION EXPERIMENTS}

The simulated experimental platform of a marine electric network - including the marine synchronous generator, as well as the linear load and nonlinear load - is established. The parameters of the simulated power source are those of a synchronous generator for marine use which is made in Shanghai Electrical Machinery Plant of Shanghai Electric Group Co., Ltd. Its type is TFH-400/6 - Salient-pole synchronous generator. Its nominal data are: $400 \mathrm{kVA}, 400 \mathrm{~V}$ line voltage, $50 \mathrm{~Hz}, 1000 \mathrm{rpm}$. Relevant reactance data are (pu): $\mathrm{d}$-axis reactance $\left(\mathrm{X}_{\mathrm{d}}\right)$ is $1.728, \mathrm{~d}$-axis transient reactance $\left(\mathrm{X}_{\mathrm{d}}{ }^{\prime}\right)$ is $0.384, \mathrm{~d}$-axis subtransient reactance $\left(\mathrm{X}_{\mathrm{d}}{ }^{\prime \prime}\right)$ is 0.1793 , q-axis reactance $\left(\mathrm{X}_{\mathrm{q}}\right)$ is 0.865 , q-axis subtransient reactance $\left(\mathrm{X}_{\mathrm{q}}{ }^{\prime}\right)$ is 0.181 , leak reactance $\left(\mathrm{X}_{1}\right)$ is 0.113 . The simulated current harmonic source is a 3-phase nonlinear load which is a 3-phase full-controlled rectification bridge circuit followed by a resistor of $10 \Omega$, and the trig angle of each of the 6 thyristors in the rectification bridge is $0^{\circ}$. The linear load is a 3-phase RL load with nominated power $20 \mathrm{kVA}$. In the shunt passive filter, the values of "L" and " $C$ " in each phase are $2 \mathrm{mH}$ and $200 \mathrm{microF}$ respectively in the 5th single-tuned harmonic filter, $2 \mathrm{mH}$ and 100 microF respectively in the 7 th single-tuned harmonic filter, and $0.37 \mathrm{mH}$ and 175 microF respectively in the high pass filter, and " $R$ " in each phase of the high pass filter is $5 \Omega$. For the PFC circuit and the SAPF, the capacitor in shunt connection in the DC side of the converter of both the PFC circuit and SAPF is 2 microF, while each phase reactance that connects the PFC circuit and the network, as well as the SAPF and the network, is $5 \mathrm{mH}$. Furthermore, for the design of the SAPF, its low-passfiltering part adopts the second filter module with its cut-off frequency $20 \mathrm{kHz}$.

The registered voltage waveform and current waveform in the sub-switchboard of the nonlinear load are shown in Fig. 3. In Fig. 3, $\mathrm{THD}_{\mathrm{V}}$ of the voltage supplied to the nonlinear load is $4.94 \%, \mathrm{THD}_{\mathrm{I}}$ of the nonlinear load harmonic current is $30.55 \%$, and the network total power factor is 0.72 .

In the simulation experiment, a comparison between the operation of a combined system of shunt passive and series active power filter and the operation of the Hybrid APF/PFC/ PPF Circuit is carried out. In the first step of the experiment, only a combined system of shunt passive and series active power filter operates in the simulated marine electric network. The experimental result of the network voltage and current waveforms and their spectrum are shown in Fig. 4. In the second step of the experiment, the Hybrid APF/PFC/PPF Circuit is put into operation in the simulated marine electric network. The experimental result of the network voltage and current waveforms and their spectrum are shown in Fig. 5. In Fig. 4, $\mathrm{THD}_{\mathrm{V}}$ of the voltage supplied to the nonlinear load is $3.89 \%$, $\mathrm{THD}_{\mathrm{I}}$ of the nonlinear load harmonic current is $12.58 \%$, and the network total power factor is 0.90 . In Fig. 5, THD of the voltage supplied to the nonlinear load is $3.13 \%, \mathrm{THD}_{\mathrm{I}}$ of the nonlinear load harmonic current is $6.19 \%$, and the network total power factor is 0.99 .

In the simulation experiment, a comparison between the operation of a combined system of shunt passive and series active power filter and the operation of the Hybrid APF/PFC/ PPF Circuit is carried out. In the first step of the experiment, only a combined system of shunt passive and series active power filter operates in the simulated marine electric network. The experimental result of the network voltage and current waveforms and their spectrum are shown in Fig. 4. In the second step of the experiment, the Hybrid APF/PFC/PPF Circuit is put into operation in the simulated marine electric network. The experimental result of the network voltage and current
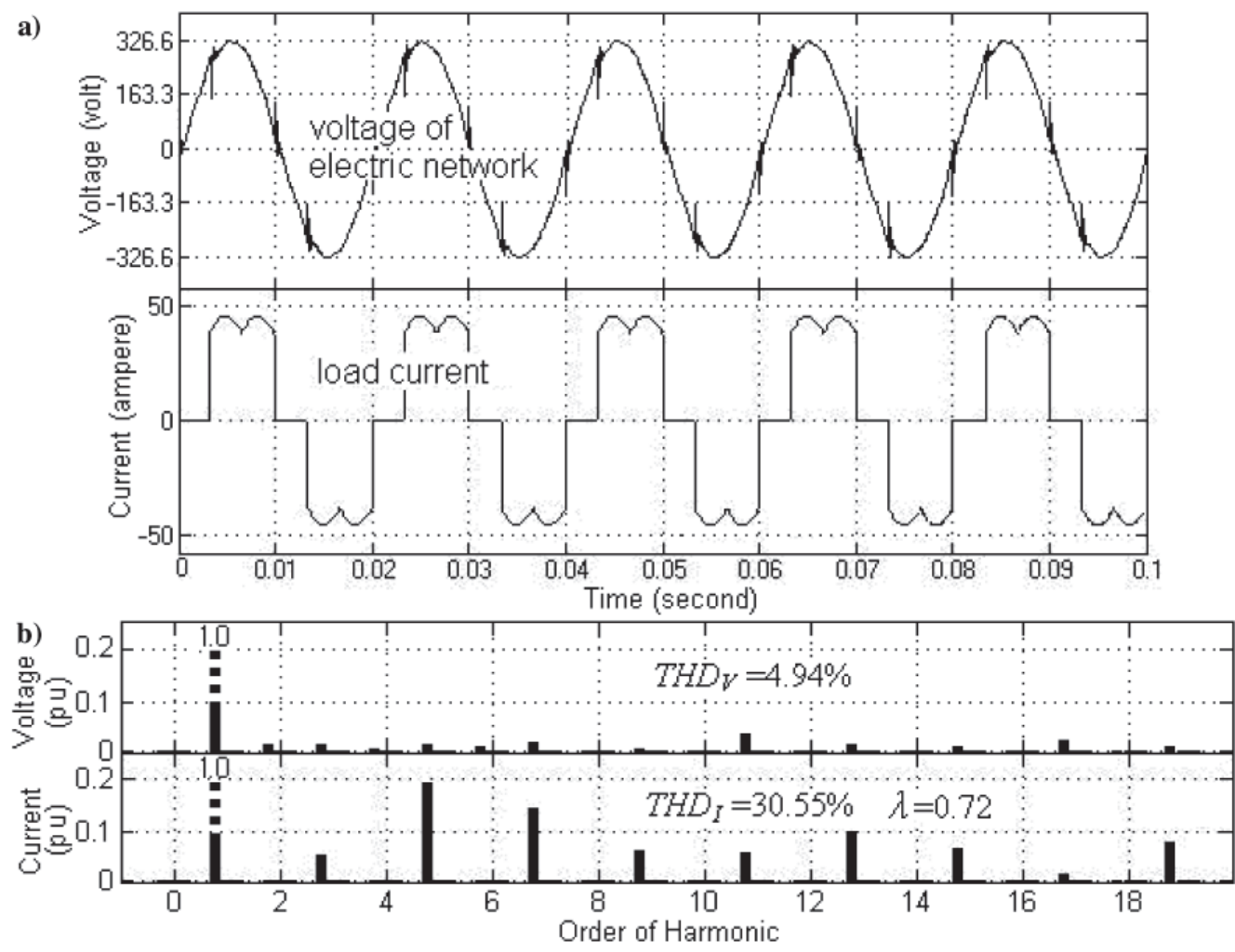

Fig. 3. Voltage and current waveforms and spectrum of harmonic source, a) waveforms of network voltage and nonlinear load current, b) spectrum analysis. 
a)

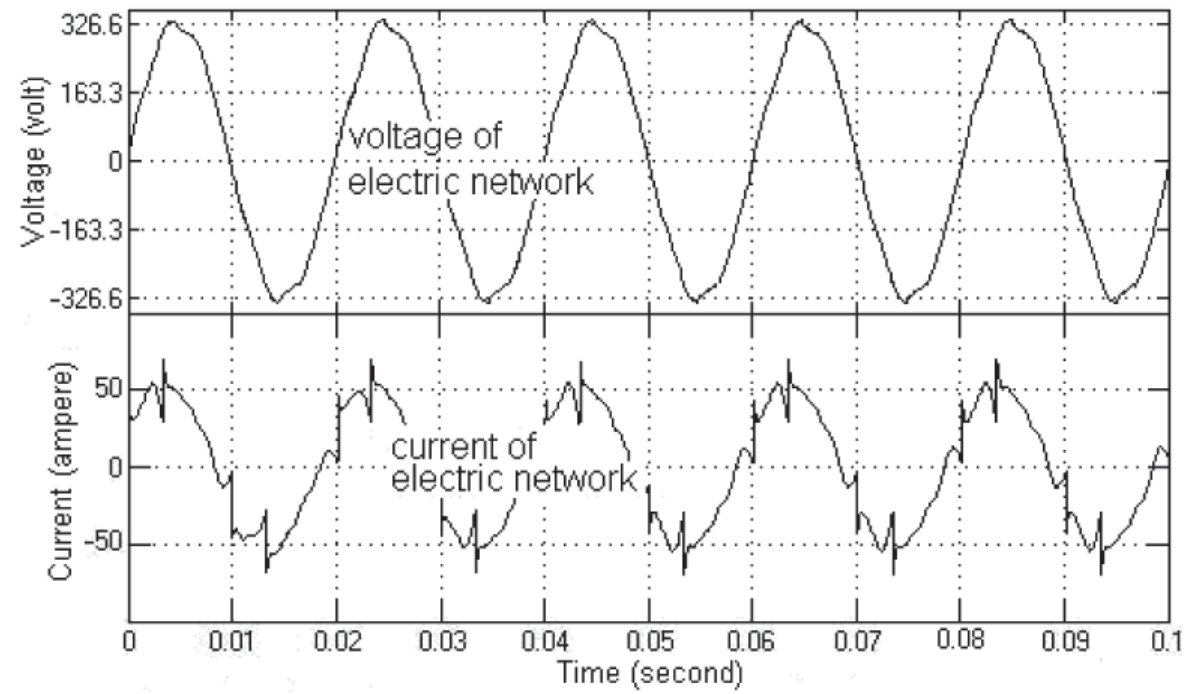

b)

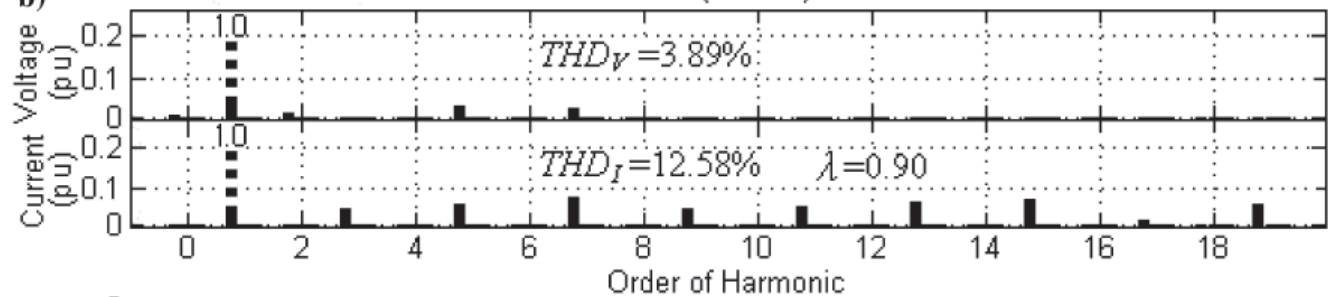

Fig. 4. Voltage and current waveforms and spectrum obtained after the operation of a combined system of shunt passive and series active power filter, a) waveforms of network voltage and current, b) spectrum analysis

a)

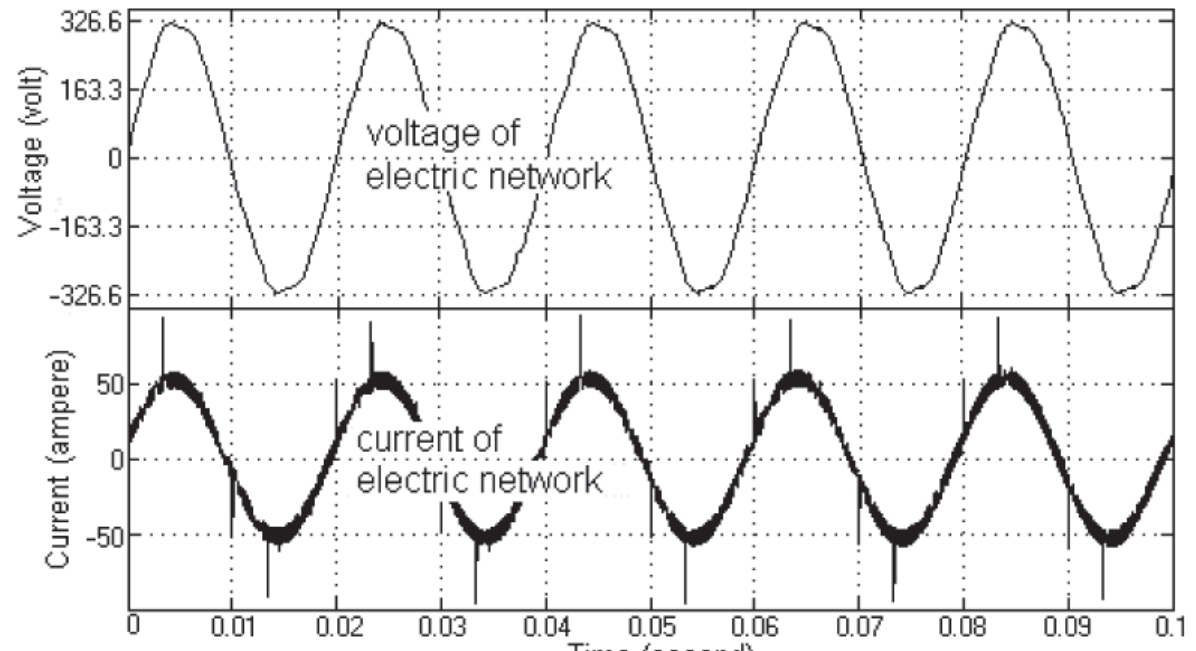

b)

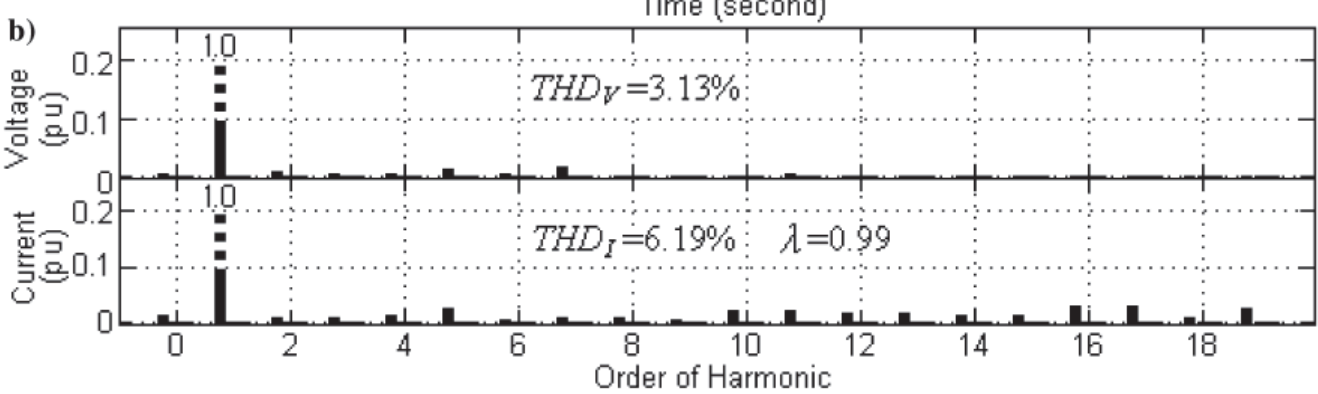

Fig. 5. Voltage and current waveforms and spectrum obtained after operation of the Hybrid APF/PFC/PPF Circuit, a) waveforms of network voltage and current, b) spectrum analysis

waveforms and their spectrum are shown in Fig. 5. In Fig. 4, $\mathrm{THD}_{\mathrm{V}}$ of the voltage supplied to the nonlinear load is $3.89 \%$, $\mathrm{THD}_{\mathrm{I}}$ of the nonlinear load harmonic current is $12.58 \%$, and the network total power factor is 0.90 . In Fig. 5, $\mathrm{THD}_{\mathrm{V}}$ of the voltage supplied to the nonlinear load is $3.13 \%$, THD $_{\mathrm{I}}$ of the nonlinear load harmonic current is $6.19 \%$, and the network total power factor is 0.99 .
The effectiveness of the filtering circuits under consideration was evaluated not only based on their filtering properties, expressed by related THD values, but also taking into consideration such parameters as $\max \left(I_{h} / I_{1}\right)$, active power factor $\lambda$, estimated cost of realization and the influence of $\Delta \mathrm{f}= \pm 5 \% \mathrm{f}_{\mathrm{n}}$ (rated frequency) changes on the filtering properties. It was verified that the efficiency of a passive parallel filter (PPF) alone is compromised 
when the frequency is deviating. So to improve this situation, a hybrid filter construction should be applied, but at least two criteria must be taken into account at the same time: harmonic mitigation and sensitivity to frequency deviation. The solution based on combined SAPF/PFC/PPF configuration displays the best ability for power quality improvement; however, it is quite an expensive solution and the most susceptible to the marine environment itself. It requires careful design and manufacture of hardware parts in order to be resistant to marine conditions, i.e. vibration, humidity, high temperature.

\section{CONCLUSION}

According to the comparison of the experimental results of network voltage and current waveforms and their spectrum in the environment of a simulated marine electric network, it can be concluded that the combined system of shunt passive and series active power filter is able to improve the network harmonics and power factor, but it is not adequately effective in suppressing current harmonics and improving the power factor. In contrast, application of the Hybrid APF/PFC/PPF Circuit gives satisfactory result in both voltage and current harmonics suppression and power factor correction. That is, due to the importance and complicated nature of the problem of marine electrical power quality, application of the designed Hybrid APF/PFC/PPF Circuit to a marine electric network to improve the problem of harmonics and low power factor is a reasonable choice since it shows considerable merits in harmonic suppression and power factor correction in the environment of a marine electric network.

\section{Acknowledgment}

This work was supported on the Chinese side by the Leading Academic Discipline Project of Shanghai Municipal Education Commission J50602 and by the S\&T Program of Shanghai Maritime University. On the Polish side this work was supported by the Polish Ministry of Sciences and Higher Education, project No $588 / \mathrm{N}-$ China/2009/0.

\section{BIBLIOGRAPHY}

1. Akagi, H., Kanazawa, Y., and Nabae, A.: 'Instantaneous reactive power compensators comprising switching devices without energy storage components', IEEE Trans. Industry Applications, 20, (3), pp. 625-630, 1984

2. Arrillaga, J., Watson, N. R., and Chen, S.: 'Power System Quality Assessment' (UK: John Wiley \& Sons, 2000)

3. Chang, G. W., and Chen, W. C.: 'A new reference compensation voltage strategy for series active power filter control', IEEE Trans. Power Delivery, 21, (3), pp. 1754-1756, 2006

4. China Classification Society, 'Guide for Harmonic Control in Ocean Ships - in Criterion of steel ocean ship classification and construction (Fascicle No. 4)' (Beijing: People's communications press, 2001), pp. 4-6, 2001

5. IEC 61000-3-3: 'Electromagnetic Compatibility (EMC), Part 3-3: Limits - Limitation of voltage changes, voltage fluctuation and flicker in public low-voltage supply systems, for equipment with rated current $<=16$ A per phase and not subject to conditional connection', 2002.

6. Kilic, T., Milun, S., and Petrovic, G.: 'Design and implementation of predictive filtering system for current reference generation of active power filter', Electrical Power and Energy Systems, 29, (2), pp. 106-112, 2007

7. Kim S., and Enjeti, P. N.: 'A new hybrid active power filter (APF) topology', IEEE Trans. Power Electronics, 17, (1), pp. 48-54, 2002

8. Luo, S., Hou, Z.: 'An adaptive detecting method for harmonic and reactive currents', IEEE Trans. Industrial Electronics, 42, (1), pp. 85-89, 1995

9. Mindykowski, J.: 'Assessment and improvement of electric power quality in ships' modern systems', Proc. 2003 Int. Marine Electrotechnology Conf. and Exhibition, Shanghai, China, Sep., pp. 8-21, 2003

10.Mindykowski, J. 'Assessment of Electric Power Quality in Ship System Fitted with Converter Subsystem' (Gdansk: Press of Shipbuilding and Shipping Ltd, 2003), pp. 1-2, 2003

11.Mindykowski, J., and Tarasiuk, T.: 'Electrical energy quality under ship's conditions'. Proc. 16th IMEKO World Congress, Vienna, vol. 7, pp. 245-250, 2000

12.Peng, F. Z., Akagi, H., and Nabae, A.: 'A new approach to harmonic compensation in power systems - a combined system of shunt passive and series active filters', IEEE Trans. Industry Applications, 26, (6), pp. 983-990, 1990

13.Pertinent rules and requirements of selected classification institutions: 'ABS, $D N V, I A C S, L R, N K K, R S$ ', (Continuously updated)

14.Lloyd's Register of Shipping: 'Rules and Regulations for Classification of Ships. Part 6, Electrical Engineering', 1996. updated 1998.

15.Salmeron, P., Herrera, R. S., and Vazquez, J. R.: 'A new approach for three-phase loads compensation based on the instantaneous reactive power theory', Electric Power Systems Research, 78, (4), pp. 605-617, 2008

16.Tarasiuk, T., Mindykowski, J., and Xu, X.: 'Facing a problem of electrical energy quality in ship networks - measurement, estimation, control', J. Shanghai Maritime University, 24, (3), pp. 193-199, 2003

17.IACS Requirements: 'Test Specification', 10th Edition (1991), Revision 2.1 (1999), Revision 3 (2000).

18.Wakileh, G. J.: 'Power Systems Harmonics - Fundamentals, Analysis and Filter Design' (Beijing: China Machine Press, 2003)

19. Yang, J., and Wang, Z.: 'A study on the comparison of two methods used to detect the harmonic currents of three-phase circuits', Trans. China Electrotechnical Society, 10, (5), pp. 4348,1995

\section{CONTACT WITH THE AUTHORS}

Xiao-Yan Xu, Prof. e-mail: xuxy@shmtu.edu.cn

Department of Mechatronics Engineering, Shanghai Maritime University, Shanghai 200135, China. Janusz Mindykowski, Prof. e-mail: janmind@am.gdynia.pl

Faculty of Marine Electrical Engineering, Gdynia Maritime University, 81-225 Gdynia, POLAND.

C. L. Philip Chen, Prof. e-mail: Philip.Chen@ieee.org Faculty of Science and Technology, University of Macau, Macau, China. 